\title{
Immobilization of Fatty Acid Synthetase from Mycobacterium smegmatis by Radiation-Induced Polymerization ${ }^{\dagger}$
}

\author{
Shintaro KikUCHI and Papachan E. KolatTukud** \\ Department of Chemical Engineering, Muroran Institute of Technology \\ Muroran, Hokkaido 050, Japan \\ * Ohio State Biotechnology Center, The Ohio State University. \\ Columbus, Ohio 43210. U.S.A.
}

Received December 4, 1989

\begin{abstract}
Fatty acid synthetase of Type I from Mycobacterium smegmatis was immobilized by radiationinduced polymerization of 2-hydroxyethyl methacrylate (HEMA) in the presence of trimethylolpropane trimethacrylate (TMPTMA). The stability of immobilized synthetase toward low ionic strength increased in comparison with the free form, but the stabilities of immobilized preparations assessed by $\mathrm{pH}$ and temperature were identical to those of the free form. The apparent $\mathrm{Km}$ of immobilized enzyme for acetyl-CoA and malonyl-CoA were both $6 \mu \mathrm{M}$, essentially the same as those of the free form; acetyl-CoA, $5 \mu \mathrm{M}$ and malonyl-CoA, $6 \mu \mathrm{M}$.
\end{abstract}

Two types of fatty acid synthetases have been isolated from Mycobacterium smegmatis; Type I, a single multifunctional polypeptide with a molecular weight of $1.7 \times 10^{6}$ involved in de novo fatty acid synthesis, and the other is Type II, a system composed of separable enzymes. ${ }^{1-6)}$ From the viewpoint of biosynthesis of fatty acids characteristic of this bacilli, it has been assumed that both types of synthetases might coordinately function, in vivo, within the framework of a highly organized, compartmentalized structure resembling immobilized enzyme systems.")

Several investigators, Kaetsu and collaborators in particular, have reported on the immobilization of enzymes and antibodies by the radiation-induced polymerization of a suitable monomer such as 2-hydroxyethyl methacrylate (HEMA) ${ }^{8-12)}$ According to them, the method is based on the physical entrapment of protein molecules in polymer matrices formed by $\gamma$-irradiation of a monomer at a low temperature. They assumed that protein would be firmly adsorbed to the polymer, not by chemical binding like covalent bond, at the surface of the pores formed by the ice crystals produced by freezing.

The study reported in this communication was done with fatty acid synthetase Type I from $M$. smegmatis immobilized using 2-hydroxyethyl methacrylate (HEMA) as the monomer and trimethylolpropane trimethacrylate (TMPTMA) as the cross-linking agent. ${ }^{12)} \mathrm{We}$ shall show the properties of immobilized synthetase and compare them with those of the free enzyme.

\section{Materials and Methods}

Chemicals. 2-Hydroxyethyl methacrylate (HEMA) was purchased from the Sigma Chernical Company and trimethylolpropane trimethacrylate (TMPTMA) was the product of the Aldrich Chemical Company. Both chemicals were used as received. $2-{ }^{14} \mathrm{C}$-malonyl-CoA, $1{ }^{14} \mathrm{C}$ acetyl-CoA, and ${ }^{3} \mathrm{H}-\beta$-alanine were purchased from $\mathrm{New}$ England Nuclear. All other chemicals were of reagent grade.

Purification of fatty acid synthetase Type I from Mycobacterium smegmatis. The fatty acid synthetase Type I was purified from $M$. smegmatis ATCC 14468, cultivated as reported previously, ${ }^{3)}$ by the method of Vance et al. ${ }^{131}$

\footnotetext{
+ This work was supported in part by a Grant-in-Aid from The Akiyama Foundation.
} 
with the following modifications. Briefly, the crude cell extracts prepared by sonic disintegration $(133 \mathrm{~W}, 20 \mathrm{kHz}$, $20 \mathrm{~min})$ was fractionated by $\left(\mathrm{NH}_{4}\right)_{2} \mathrm{SO}_{4}$. A $35-55 \%$ saturated fraction was then put on a column of DEAEcellulose $(1.5 \times 25 \mathrm{~cm})$ after dialysis, and eluted with a linear concentration gradient of potassium phosphate buffer, $\mathrm{pH} 7.2$, from $0.25 \mathrm{M}$ to $0.7 \mathrm{M}$. Eluate containing de novo fatty acid synthetase activities assayed as described below were pooled and fractionated again by $\left(\mathrm{NH}_{4}\right)_{2} \mathrm{SO}_{4}$ A $0-60 \%$ saturated fraction was then put on a column of Bio-Gel A5m $(1.5 \times 60 \mathrm{~cm})$ after dialysis and eluted with

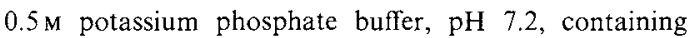
$2 \mathrm{~mm}$ dithiothreitol. The purified preparation gave a single band on SDS-polyacrylamide slab gel electrophoresis. Tritium-labeled fatty acid synthetase was purified as described above from $M$. smegmatis cells grown on a medium containing ${ }^{3} \mathrm{H}-\beta$-alanine, which was prepared by the method of Matsumura et al. ${ }^{1)}$

Production of antiserum. Polyclonal antiserum to the purified fatty acid synthetase was raised in male New Zealand white rabbits. About $4 \mathrm{mg}$ of synthetase was emulsified in complete Freund's adjuvant and injected subcutaneously at multiple sites on the back. After three weeks a second injection, in incomplete Freund's adjuvant, was given intramuscularly. Further booster injections were given in saline. The total immunoglobulins were precipitated from antiserum with $\left(\mathrm{NH}_{4}\right)_{2} \mathrm{SO}_{4}$. FITC (fluorescein isothiocyanate)-labeled immunoglobulins were prepared by the method of Weigele et al. ${ }^{14)}$

Immobilization of the fatty acid synthetase. Immobilization of the purified fatty acid synthetase was done by the method reported previousiy ${ }^{10}$ with the following modifications: $1 \mathrm{ml}$ of 2-hydroxyethylmethacrylate (HEMA), $5 \mu \mathrm{l}$ of trimethylolpropane trimethacrylate (TMPTMA), and the purified synthetase preparation in $1 \mathrm{ml}$ of $2 \mathrm{~mm}$ DTT $-0.1 \mathrm{~m}$ potassium phosphate buffer, $\mathrm{pH}$ $7.2,(20.3 \mathrm{mg}$ protein per milliliter $)$ were placed in a glass tube with $20 \mathrm{~mm}$ in diameter, degassed, frozen at $-75^{\circ} \mathrm{C}$, and irradiated with $\gamma$-rays at a dose of $1 \times 10^{6}$ rad. Membrane discs were sliced from the frozen polymer gel into $150 \mu \mathrm{m}$ thickness with a microtome, and then rinsed in $500 \mathrm{ml}$ of $2 \mathrm{~mm} \mathrm{DTT}-0.1 \mathrm{M}$ potassium phosphate buffer, $\mathrm{pH} 7.2$, for $30 \mathrm{~min}$ at $4^{\circ} \mathrm{C}$ with gentle shaking. Portions of the membrane discs were examined with a light microscope and an immuno-fluorescent one with a $12.5 \times \mathrm{mag}$ nification eyepiece and $10 \times$ magnification objective, and photographs were taken.

Assay of fatty acid synthetase activity. The standard assay mixture contained $0.1 \mathrm{mmol}$ of potassium phosphate buffer, $\mathrm{pH} 7.2,1 \mu \mathrm{mol}$ of EDTA, $1 \mu \mathrm{mol}$ of DTT, $10 \mathrm{nmol}$ of FMN, $25 \mathrm{nmol}$ of acetyl-CoA, $25 \mathrm{nmol}$ of $2-{ }^{14} \mathrm{C}$ malonyl-CoA (Sp. Act. $0.4 \mathrm{Ci} / \mathrm{mol}$ ), and $250 \mathrm{nmol}$ of NADPH in a final volume of $0.9 \mathrm{ml}$. The mixture was held for $5 \mathrm{~min}$ at $37^{\circ} \mathrm{C}$, and then $0.1 \mathrm{ml}$ of the free synthetase solution or a membrane disc in $0.1 \mathrm{ml}$ of $2 \mathrm{~mm} \mathrm{DTT}-0.1 \mathrm{M}$ potassium phosphate buffer, $\mathrm{pH} 7.2$, was added to start the reaction. The reaction for the free synthetase assay was done with shaking, while the mixture for the immobilized synthetase assay was stirred magnetically using a small Tefon-coated magnetic bar. The activities of both fatty acid synthetases were measured by the radioactivities incorporated into the $n$-pentane-extractable portion as described previously. ${ }^{3-6)}$ Fatty acid synthetase activities retained by matrices were measured after washing the discs several times described above. To calculate the $\mathrm{Km}$ of free or immobilized synthetase for malonyl-CoA, $2-{ }^{14} \mathrm{C}$ malonyl-CoA was replaced by non-labeled malonyl-CoA and $1-{ }^{14} \mathrm{C}$-acetyl-CoA (Sp. Act. $0.8 \mathrm{Ci} / \mathrm{mol}$ ) was used, but the other conditions were the same as the standard mixture. Thermostability of free or immobilized synthetase was measured by heating; several tubes containing free enzyme (about $0.7 \mathrm{mg}$ ) in $1 \mathrm{ml}$ of $2 \mathrm{~mm}$ DTT $-0.1 \mathrm{M}$ potassium phosphate buffer, $\mathrm{pH} 7.2$, or membrane discs in $1 \mathrm{ml}$ of the same buffer were heated for $20 \mathrm{~min}$ at the temperature specified and chilled. A sample $(100 \mu 1)$ of free enzyme or a membrane disc was withdrawn from each tube and the enzyme activity left after the heat treatment was assayed. To measure the $\mathrm{pH}$-stability of synthetase, free or immobilized enzyme preparations were dialyzed against or suspended in $1000 \mathrm{ml}$ of $2 \mathrm{~mm}$ DTT $-0.1 \mathrm{M}$ potassium phosphate buffer, $\mathrm{pH}$-specified, for $5 \mathrm{hr}$ at $4^{\circ} \mathrm{C}$, and the enzyme activity after the treatment was assayed. For an investigation of stabilities of free and immobilized synthetases in low concentrations of buffer, both preparations were dialyzed against $1000 \mathrm{ml}$ of $2 \mathrm{~mm}$ DTT $-0.05 \mathrm{M}$ potassium phosphate buffer, $\mathrm{pH} 7.2$, for various periods at $4^{\circ} \mathrm{C}$ and assayed.

Identification and characterization of reaction products. Reaction products were identified radio-gas-liquid chromatographically as described previously. ${ }^{5.6)}$ After extracting the saponifiable lipids with $n$-pentane, the solvent was evaporated and residual fatty acids were methylated with $15 \%(\mathrm{w} / \mathrm{v}) \mathrm{BF}_{3}$ in methanol by the method of Metcalfe and Schmitz ${ }^{15}$ and then radio-gas-liquid chromatographed using a Packard 894 proportional counter connected to a Shimadzu 6AM gas-liquid-chromatograph. Products of the immobilized synthetase were identified as free acids or $\mathrm{CoA}$ derivatives by the method of Stampf et $a l^{16)}$

\section{Results and Discussion}

\section{Immobilization of fatty acid synthetase}

A mixture containing a $1: 1$ ratio (in volume) of HEMA and synthetase solution was chosen since it appeared the most suitable for the immobilization of other enzymes. ${ }^{8-12)}$ Photomicrographs of the structure of the matrix polymerized under this condition and the 

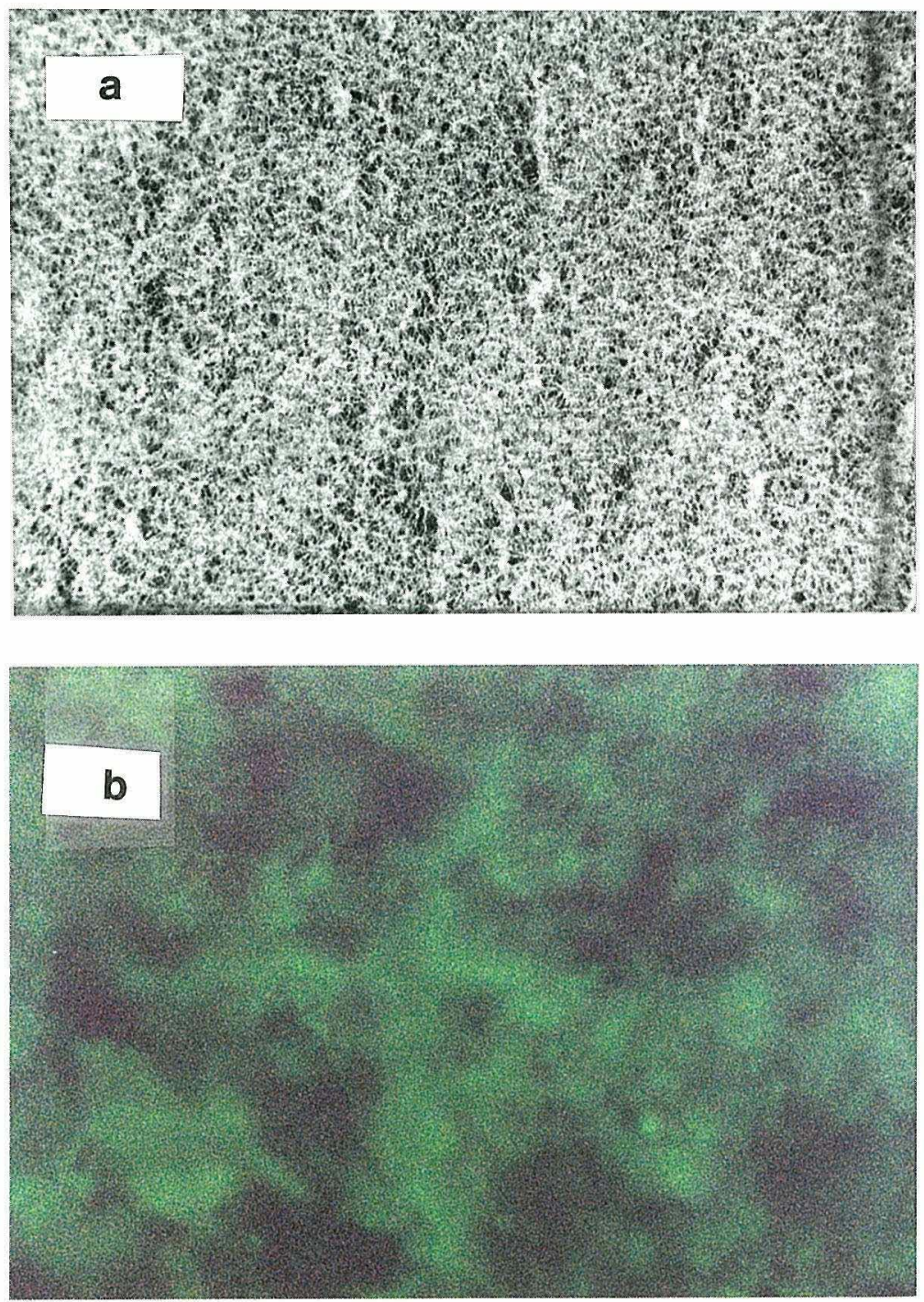

Fig. 1. Optical and Immunofluorescent Micrographs of the Polymer Matrix.

(a), an optical micrograph; (b), a fluorescent micrograph stained with FITC-conjugated anti-fatty acid synthetase-rabbit serum.

distribution of synthetase on the matrix, which was detected by immunofluorescence, are shown in Fig. 1. The leakage of synthetase from the matrix was also examined because rapid protein leakage from the radiationinduced polymerized matrices were reported in cases of enzymes such as glucoamylase and penicillin acylase. ${ }^{9,12)}$ Since protein from the support matrices can not be measured, in general, by the common protein assay methods such as dye-binding or Folin-Lowry, this was done radiochemically using ${ }^{3} \mathrm{H}$-alanine labeled synthetase. As shown in Fig. 2, the synthetase immobilized without TMPTMA was rapidly washed off from the matrix after the first three washings. In contrast, the addition of a small amount of TMPTMA $(0.5 \%$, with respect to the monomer volume), which has three double bonds per molecule, caused a significant improvement in the property of the matrix. Although the availability of TMPTMA as the cross-linking agent was first observed by 


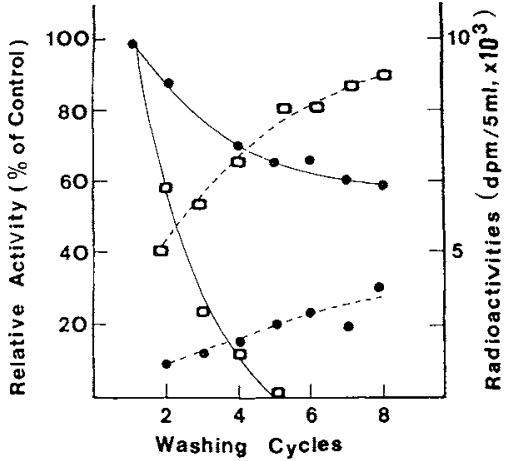

Fig. 2. Fatty Acid Synthetase Activity Retained by the Matrix.

The membrane discs, prepared in the presence (C) or the absence ( $\square$ ) of TMPTMA, were repeatedly washed as described in Materials and Methods. The relative activities were calculated from radioactivities incorporated into saponifiable lipids with one-time-washed preparations (they were $5620 \mathrm{dpm}$ and $5480 \mathrm{dpm}$ in the presence of TMPTMA and in the absence of TMPTMA, respectively) (fine lines). Total radioactivities released by washings into the buffer from the matrix immobilized ${ }^{3} \mathrm{H}$-labeled synthetase were also measured (dotted lines).

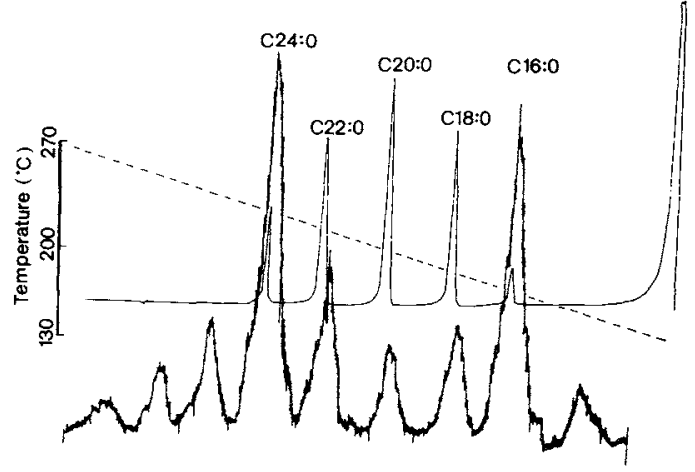

Fig. 3. Radio-gas-liquid Chromatography of Fatty Acids from Acetyl-CoA and $2-{ }^{14} \mathrm{C}$-malonyl-CoA with the Immobilized Synthetase.

A sample was chromatographed with authentic methyl esters of $\mathrm{C} 16: 0, \mathrm{C} 18: 0, \mathrm{C} 20: 0, \mathrm{C} 22: 0$ and $\mathrm{C} 24: 0$ under temperature-programmed conditions $\left(130-270^{\circ} \mathrm{C}, 6^{\circ} \mathrm{C} /\right.$ min, dotted line). Fine and thick lines in the figure indicate gas-chromatographic and radioactivity scanning curves, respectively.

Boccu et al. for the immobilization of penicillin acylase and assumed to be related to the tridimensional arrangement of the network structure of matrix ${ }^{12)}$ the actual reason for the increased retention of enzyme is not clear.

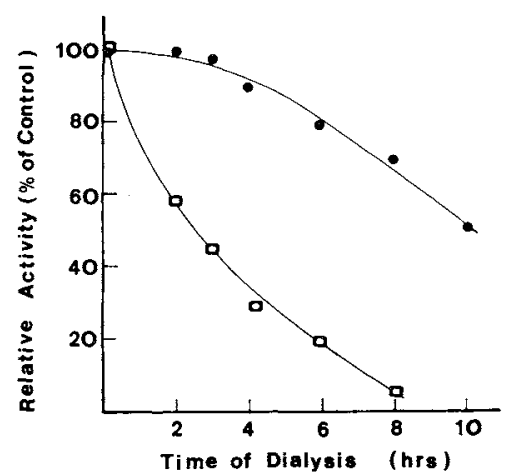

Fig. 4. Inactivation of Fatty Acid Synthetase by Altering the Potassium Phosphate Concentration.

The free ( $\square$ ) and immobilized (-) synthetases were dialyzed against $1000 \mathrm{ml}$ of $2 \mathrm{~mm}$ DTT $-0.05 \mathrm{M}$ potassium phosphate buffer, $\mathrm{pH} 7.2$, at $4^{\circ} \mathrm{C}$ for the indicated periods and assayed. The relative activities were calculated from radio-activities incorporated into saponifiable lipids with non-dialyzed preparations; they were $17470 \mathrm{dpm}$ and $5530 \mathrm{dpm}$ for free and immobilized synthetase, respectively.

Identification and characterization of reaction products by immobilized synthetase

The reaction products from acetyl-CoA and $2-{ }^{14} \mathrm{C}$-malonyl-CoA by the immobilized synthetase were identified radio-gas-liquid chromatographically as long-chain fatty acids such as palmitate, stearate, arachidate, behenate, and lignocerate (tetracosanate) (Fig. 3) like the products by the free enzyme. ${ }^{7)}$ Simultaneously, it is shown in Fig. 3 that the pattern of products by immobilized synthetase was bimodal, consisting of palmitate and lignocerate as the two principal products, as was also observed for the free enzyme. ${ }^{2.7)}$ Furthermore, it was also confirmed by the method described in Materials and Methods that more than $95 \%$ of the products of immobilized synthetase appeared in the reaction mixture as $\mathrm{CoA}$ derivatives, not free acid forms, like the products of free synthetase (data was not shown).

\section{Stability of the immobilized synthetase}

Vance et al. have investigated the response of the Type I synthetase from $M$. smegmatis to ionic strength and showed that the synthetase was unstable and inactivated in phosphate buffer below $0.1 \mathrm{M}^{13)}$ They have concluded 


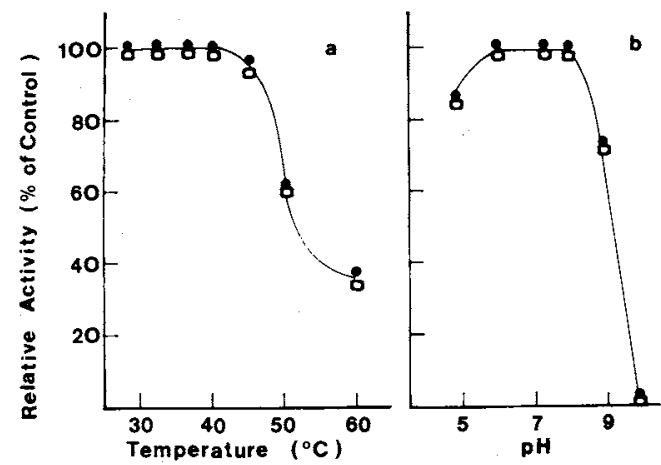

Fig. 5. Stability of Fatty Acid Synthetase to Temperature or $\mathrm{pH}$.

The free $(\square)$ and immobilized (O) synthetase was either heated for $20 \mathrm{~min}$ at the indicated temperature, chilled and assayed (a), or incubated at $4^{\circ} \mathrm{C}$ for $5 \mathrm{hr}$ at the indicated $\mathrm{pH}$ and assayed (b). The relative activities were calculated from radioactivities incorporated into saponifiable lipids with non-heat-treated preparations $(17320 \mathrm{dpm}$ or 5580 dpm for free or immobilized enzyme, respectively), or with non-pH-treated preparations $(17220 \mathrm{dpm}$ or $5600 \mathrm{dpm}$ for free or immobilized enzyme, respectively).

that this effect on catalytic activity was caused by a dissociation of the synthetase into an enzymatically inactive species at low concentrations of phosphate buffer. This was also observed in our study as shown in Fig. 4; the free synthetase rapidly lost its activity on dialysis against $2 \mathrm{~mm}$ DTT $-0.05 \mathrm{M}$ phosphate

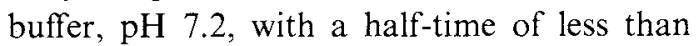
$3 \mathrm{hr}$ and almost all activity had disappeared after $8 \mathrm{hr}$ of dialysis. In contrast, the immobilized synthetase was fully active by treatment with the buffer for $3 \mathrm{hr}$ and had lost about half of its activity after $10 \mathrm{hr}$ of treatment. The stability of immobilized synthetase was further studied with respect to temperature and $\mathrm{pH}$. The results obtained with free and immobilized synthetase exposed to various degrees of temperature and $\mathrm{pH}$ for fixed periods of time are shown in Fig. 5a, b, respectively. The two forms have identical patterns of inactivation toward these factors.

$\mathrm{Km}$ for acetyl-CoA or malonyl-CoA of the immobilized synthetase

Lineweaver-Burk plots of free or immobilized synthetase for acetyl-CoA and malonyl-
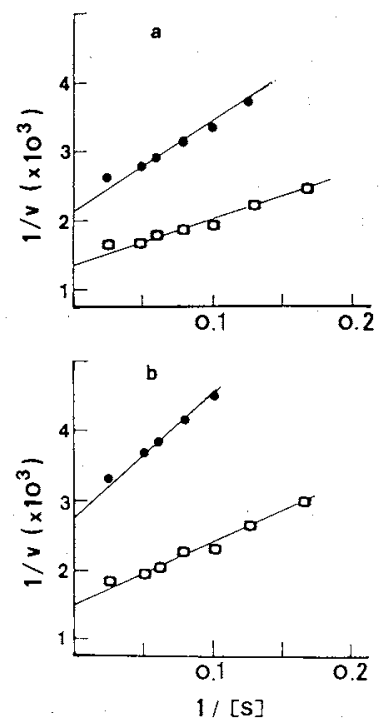

Fig. 6. Lineweaver-Burk Plots of Fatty Acid Synthetase.

The activity was assayed as in Materials and Methods with various concentrations of acetyl-CoA (a) and malonylCoA (b): $\square$, free and; $\boldsymbol{O}$, immobilized synthetase.

CoA are shown in Fig. 6a, b, respectively. The apparent $\mathrm{Km}$ of the immobilized synthetase for acetyl-CoA $(6 \mu \mathrm{M})$ and malonyl-CoA $(6 \mu \mathrm{M})$ were similar to those of the free one; acetylCoA, $5 \mu \mathrm{m}$ and malonyl-CoA, $6 \mu \mathrm{m}$. Mikkelsen et al. reported recently, using rat liver fatty acid synthetase immobilized immunochemically to Sepharose 4B, that the $K m$ of immobilized synthetase for acetyl-CoA and malonylCoA were almost identical to those of the free form and the reaction was not limited by diffusion of substrates and/or products. ${ }^{20)}$ Laidler and collaborators described how the Lineweaver-Burk plots of enzyme immobilized on membrane supports should be somewhat convex to the $1 /[\mathrm{S}]$ axis when there was diffusion limitation, the degree of convexity depending on the extent of the limitation. ${ }^{17-19)}$ In this study, the plots of the immobilized synthetase for acetyl-CoA and malonyl-CoA were not convex to the $1 /[\mathrm{S}]$ axis, being identical to those of the free form with regard to the convexity. These results strongly suggested that there was no diffusion limitation of substrates and/or products in this 
study of the immobilized synthetase.

To our knowledge, this study in this communication is the first application of radiationinduced polymerization to immobilize a highmolecular-weight and complex structural entity, Type I fatty acid synthetase, although further investigations should be necessary for elucidating its biochemical and bioengineering properties.

Acknowledgments. The authors wish to thank Dr. T. Ohnishi of the Isotope Research Center, Hokkaido University, for kindly doing the irradiation with $\gamma$-rays and for his helpful discussions.

\section{References}

1) D. N. Brindley, S. Matsumura and K. Bloch, Nature, 244. 666 (1969).

2) J. M. Odriozola, J. M. Ramos and K. Bloch, Biochim. Biophys. Acta, 488, 207 (1977).

3) S. Kikuchi and T. Kusaka, J. Biochem., 92, 839 (1982).

4) S. Kikuchi and T. Kusaka, J. Biochem., 94, 1045 (1983).

5) S. Kikuchi and T. Kusaka, J. Biochem., 96, 841 (1984).

6) S. Kikuchi, T. Takeuchi, M. Yasui, T. Kusaka and P.
E. Kolattukudy, Agric. Biol. Chem., 53, 1689 (1989).

7) C. Ratledge, in "The Biology of the Mycobacteria," Vol. 1, ed. by C. Ratledge and J. Standford, Academic Press, New York, 1982, pp. 53-93.

8) M. Nakamura, M. Yoshida and I. Kaetsu, Biotechnol. Bioeng., 21, 679 (1979).

9) M. Yoshida and I. Kaetsu, J. Appl. Polymer Sci., 26, 687 (1981).

10) I. Kaetsu, M. Kumakura, S. Kikuchi, S. Adachi and M. Suzuki, Z. Naturforsch., 38c, 812 (1983).

11) M. Kumakura, I. Kaetsu and T. Kobayashi, Enzyme Microbiol. Technol., 6, 23 (1984).

12) E. Boccu, M. Carenza, S. Lora, G. Palma and F. M. Verornese, Appl. Biochem. Biotechnol., 15, 1 (1987).

13) D. E. Vance, O. Mitsuhashi and K. Bloch, J. Biol. Chem., 248, 2303 (1973).

14) M. Weigele, S. De Bernardo and W. Leimgruber, Biochem. Biophys. Res. Commun., 54, 899 (1973).

15) L. D. Metcalfe and A. A. Schmitz, Anal. Chem., 33, 363 (1961).

16) M. Mamcha, G. B. Stokes and P. K. Stampf, Anal. Biochem., 68, 600 (1975).

17) P. S. Bunting and K. J. Laidler, Biochemistry, 11, 4477 (1972).

18) T. T. Ngo and K. J. Laidler, Biochim. Biophys. Acta, 377, $317(1975)$.

19) T. T. Ngo, P. S. Bunting and K. J. Laidler, Can. J. Biochem., 53, 11 (1975).

20) J. Mikkelsen, J. Knudsen and S. Smith, J. Biol. Chem., 262, 1566 (1987). 